\title{
Blood cell ratios in patients with primary acquired nasolacrimal duct obstruction
}

\author{
Mahmut Atum ${ }^{\circledR}$, Gürsoy Alagöz ${ }^{\circledR}$ \\ Department of Ophthalmology, Sakarya University Education and Research Hospital, Sakarya, Turkey
}

\begin{abstract}
BACKGROUND: In this study, we aimed to measure neutrophil-to-lymphocyte ratio (NLR), platelet-to-lymphocyte ratio (PLR) and mean platelet volume (MPV) levels in primary acquired nasolacrimal duct obstruction (PANDO) patients and to determine whether there it could be used as a marker for PANDO.

MATERIAL AND METHODS: This retrospective study included 61 patients with PANDO and 65 healthy controls. Data were excluded from the file records of patients who underwent external dacryocystorhinostomy (DCR). Blood samples were obtained from venous blood and serum neutrophil, lymphocyte, and platelet data of all patients were recorded and also, NLR-PLR values were calculated.

RESULTS: There was no significant difference between PANDOs and controls in terms of gender and age ( $\mathrm{p}>0.05)$. Neutrophil-to-lymphocyte was significantly increased in PANDOs compared to the controls $(\mathrm{p}<0.05)$. There was no statistically significant difference between PANDOs and controls in term of PLR ( $p>0.05)$. The average MPV in the PANDOs was found to be significantly lower than controls $(\mathrm{p}<0.05)$

CONCLUSION: Neutrophil-to-lymphocyte ratio and MPV counts were associated with PANDO.
\end{abstract}

KEY WORDS: neutrophil-to-lymphocyte ratio; platelet-to-lymphocyte ratio; mean platelet volume; primary acquired nasolacrimal duct obstruction

Ophthalmol J 2020; Vol. 5, 76-80

\section{INTRODUCTION}

Epiphora develops after obstruction of nasolacrimal canal and this condition is common in society. Acquired nasolacrimal duct obstructions are divided into two; primary and secondary. Primary acquired nasolacrimal duct obstruction (PANDO) is the most common type and especially seems after the age of 50 years. Primary acquired nasolacrimal duct obstruction is known to be more common in women than men (3-fold) [1]. Pathological studies showed that PANDO develops as a result of fibrous obstruction secondary to chronic inflammation [2-4].

Neutrophil-to-lymphocyte ratio (NLR) and platelet-to-lymphocyte ratio (PLR), calculated from hemogram are systemic inflammatory responses. Many different studies published before have shown that NLR and PLR are indicative of systemic inflammation [5-10].

Mean platelet volume (MPV) is a parameter that indicates the status of platelets, and MPV is associated with inflammation [11].

According to our literature review, there are different studies researched the association between NLR, MPV, PLR and many diseases but, there was no study to measure/examine NLR, MPV, PLR levels in PANDO disease. In this study, we purposed to measure NLR, PLR and MPV levels in PANDO patients and to determine whether there is a significant change. 


\section{MATERIAL AND METHODS}

This retrospective case-control study was conducted at Sakarya University Training and Research Hospital, Ophthalmology Clinic between January and November 2019. Data were excluded from the file records of patients who underwent external dacryocystorhinostomy (DCR) between January 2017 and November 2018. Our study was carried out according to the ethical principles set out in the Helsinki Declaration and the consent was obtained from Sakarya University Medical School Ethics Committee. The study included 61 patients with PANDO and 65 healthy controls. Healthy control patients consisted of persons with senile cataract or refractive error in ophthalmology outpatient clinic. Age and sex-matched in two groups.

Criteria for inclusion were: patients with PANDO and operated by standard external DCR technique. Criteria for exclusion were: traumatic etiology, cancer history, systemic diseases (such as cardiovascular diseases and diabetes), history of cerebrovascular disease, blood diseases, acute/chronic kidney failure.

Hemogram parameters of all cases were measured by Cell-DYN 3700 (Cell-DYN 3700, Abbott Diagnostics, Abbott Park, IL, USA) automated hematology analyzer. According to the results of hemogram; neutrophil, lymphocyte, MPV and platelet counts of all the cases were recorded and NLR-PLR values were calculated.

\section{STATISTICAL ANALYSIS}

Data analyzed due to the SPSS software (version 17.0, SPSS Inc., Chicago, IL, USA) program. Data were also reported as mean and standard deviation $( \pm$ SD). Comparison of the independent groups was done by parametric Student t-test. The cut-off point between PANDOs and controls determined due to receiver operating characteristic (ROC) curve analysis. According to the cut-off value, sensitivity and specificity values were calculated. $\mathrm{P}<0.05$ was considered significant.

\section{RESULTS}

Our study consisted of a total of 126 people, including 61 patients with PANDO and 65 healthy controls. The gender distribution of patients in PANDOs and controls was 17 male/44 female and 23 male/42 female, respectively. The mean age of the PANDOs was $53.21 \pm 14.23$ years and the controls were $55.29 \pm 8.60$ years. Primary acquired nasolacrimal duct obstruction group and controls were similar in terms of gender, age, and systemic diseases (diabetes, hypertension) ( $p>0.05)$ (Tab. 1).

The mean WBC count was $7.44 \pm 2.0710^{9} / \mathrm{L}$ in the PANDOs and $7.28 \pm 2.1810^{9} / \mathrm{L}$ in the controls and the difference between the groups was not significant $(\mathrm{p}=0.678)$. The mean neutrophil count was $4.34 \pm 1.6010^{9} / \mathrm{L}$ in the PANDOs and $3.94 \pm 1.4410^{\circ} / \mathrm{L}$ in the controls and the difference between the groups was not significant $(\mathrm{p}=0.146)$. The mean lymphocyte count was $2.34 \pm 0.7410^{\circ} / \mathrm{L}$ in the PANDOs and $2.54 \pm 1.0510^{\circ} / \mathrm{L}$ in the controls and the difference between the groups was not significant $(\mathrm{p}=0.232)$.

The mean platelet count was $245.72 \pm 57.0410^{\circ} / \mathrm{L}$ in the PANDOs and $246.27 \pm 56.4210^{\circ} / \mathrm{L}$ in the controls and the difference between the groups was not significant $(\mathrm{p}=0.956)$. The mean NLR was $1.99 \pm 0.89$ in the PANDOs and $1.69 \pm 0.66$ in the controls. NLR was significantly higher in the PANDOs than in the controls $(\mathrm{p}=0.032)$. The mean PLR was $112.74 \pm 35.93$ in the PANDOs and $108.77 \pm 40.05$ in the controls and the difference between the groups was not significant $(\mathrm{p}=0.560)$. The mean MPV was $8.00 \pm 1.55 \mathrm{fL}$ in the PANDOs and $9.01 \pm 1.77 \mathrm{fL}$ in the controls. MPV was signifi-

\begin{tabular}{|l|c|c|c|}
\hline Table 1. Demographic features in the primary acquired nasolacrimal duct obstruction (PANDO) and control groups \\
\hline & $\begin{array}{c}\text { PAND0 } \\
\text { ( } \mathbf{n = 6 1 )}\end{array}$ & $\begin{array}{c}\text { Control } \\
\text { ( } \mathbf{n}=\mathbf{6 5}\end{array}$ & $\mathbf{p}^{*}$ \\
\hline Age (years) & $53.21 \pm 14.23$ & $55.29 \pm 8.60$ & 0.320 \\
\hline Sex & & & 0.369 \\
\hline Male & 17 & 23 & \\
\hline Female & 44 & 42 & 0.354 \\
\hline DM & 6 & 10 & 0.525 \\
\hline HT & 7 & 10 & \\
\hline
\end{tabular}

DM — diabetes mellitus; HT — hypertension; "independent samples t-test 


\begin{tabular}{|l|c|c|c|}
\hline \multicolumn{2}{|l|}{ Table 2. Laboratory findings in the primary acquired nasolacrimal duct obstruction (PAND0) and control groups } \\
\hline WBC $\left[10^{9} / \mathrm{L}\right]$ & $\begin{array}{c}\text { PANDO } \\
\text { (n= 61) }\end{array}$ & $\begin{array}{c}\text { Control } \\
\text { (n=65) }\end{array}$ & $\mathbf{p}^{*}$ \\
\hline Neutrophil $\left[10^{9} / \mathrm{L}\right]$ & $7.44 \pm 2.07$ & $7.28 \pm 2.18$ & 0.678 \\
\hline Lymphocyte $\left[10^{9} / \mathrm{L}\right]$ & $4.34 \pm 1.60$ & $3.94 \pm 1.44$ & 0.146 \\
\hline Platelet $\left[10^{9} / \mathrm{L}\right]$ & $2.34 \pm 0.74$ & $2.54 \pm 1.05$ & 0.232 \\
\hline NLR & $245.72 \pm 57.04$ & $246.27 \pm 56.42$ & 0.956 \\
\hline PLR & $1.99 \pm 0.89$ & $1.69 \pm 0.66$ & 0.032 \\
\hline MPV $[\mathrm{fL}]$ & $112.74 \pm 35.93$ & $108.77 \pm 40.05$ & 0.560 \\
\hline
\end{tabular}

WBC — white blood cell; NLR — neutrophil-to-lymphocyte ratio; PLR — platelet-to-lymphocyte ratio; MPV — mean platelet volume; "independent samples $t$ test

Table 3. Receiver operating characteristic (ROC) curve analyses of neutrophil-to-lymphocyte ratio (NLR), platelet-to-Iymphocyte ratio (PLR) and mean platelet volume (MPV) in primary acquired nasolacrimal duct obstruction (PAND0)

\begin{tabular}{|l|c|c|c|c|}
\hline & AUC & Cut off & Sensitivity & Specificity \\
\hline NLR & 0.597 & 1.77 & 0.57 & 0.62 \\
\hline PLR & 0.536 & 107.99 & 0.55 & 0.53 \\
\hline MPV & 0.735 & 8.22 & 0.70 & 0.72 \\
\hline
\end{tabular}

AUC - area under curve

cantly decreased in the PANDOs than the controls $(\mathrm{p}=0.001)($ Tab. 2).

In the ROC analysis, area under curve (AUC) for NLR was 0.597 , the cut-off value was 1.77 , the sensitivity was $57 \%$, and the specificity was $62 \%$ (95\% CI: 0.498-0.696). The area under curve for PLR was 0.536, the cut-off value was 107.99 , the sensitivity was $55 \%$, and the specificity was $53 \%$ (95\% CI: 0.434-0.637). The AUC for MPV was 0.735 , the cut-off value was 8.22 , the sensitivity was $70 \%$, and the specificity was $72 \%$ (95\% CI: 0,645-0,824) (Tab. 3).

\section{DISCUSSION}

According to studies in the literature, this is the first study investigating the relationship between NLR, PLR, MPV and PANDO. The present study showed us that NLR and MPV were associated with PANDO; however, the relationship between PLR and PANDO was not seen in this study.

Primary acquired nasolacrimal duct obstruction is the main cause of nasolacrimal duct obstruction in adult humans. Previous studies have shown that PANDO develops secondary to chronic inflammation [2-4]. In addition, some studies in different diseases indicate that NLR, PLR and MPV can be used to predict inflammation [5, 7-11].
The neutrophil-lymphocyte ratio is considered an easy and practical indicator of systemic inflammation. Some studies have shown that NLR can be used as a prognostic indicator in coronary artery disease, Behçet's disease, rheumatoid arthritis and some malignancies [5, 12-16]. Systemic inflammation typically involves lymphopenia and neutrophilia [17]. Alan et al. reported that the NLR levels was increased in patients with Behçet's syndrome than controls [15]. In our study, NLR was significantly increased in PANDOs compared to control patients, and we think this might be used to predict the development of nasolacrimal duct obstruction.

The PLR is cheap, and giving some information about condition of platelets and white cells. Platelet-to-lymphocyte ratio is a predictor that has been studied in recent years and has shown the systematic inflammation (presence and severity) [18]. The relationship between PLR and various cancer types and acute coronary syndrome has been reported in previous $[19,20]$. There are studies reporting that PLR is a negative prognostic factor in some inflammatory conditions [21, 22] Azab et al. reported a relationship between increased PLR and long-term mortality in patients with myocardial infarction [10]. In another study, it was found that elevation in PLR was associated with non-dipper status in hypertensive patients [23]. In our study, 
there was no increase or decrease in PLR levels in the patient group because there was no significant change in platelet and lymphocyte counts in both groups.

Mean platelet volume is being used as a new indicator of inflammation. Inagaki et al. found that MPV levels were significantly decreased in the advanced non-small cell lung cancer group than the controls [24]. In addition, Kisacik et al. showed that MPV was significantly decreased in patients with ankylosing spondylitis and rheumatoid arthritis as compared to controls [25]. In our study, we found that in MPV levels were significantly decreased in PANDOs than the controls. The best-known effects of inflammatory disorders on hematopoiesis are anemia and thrombocytosis [26, 27]. It has been demonstrated in previous studies that MPV reflects platelet activation [28-31]. These studies suggest that there is a relationship between inflammatory diseases and MPV. In our study, we can link the statistically significant low occurrence of MPV to this mechanism.

The limitations of the study are the small patient number and retrospective design of the study. New studies involving more patients are needed to analyze the relationship between serum blood ratios and PANDO. However, further prospective studies are needed.

\section{Acknowledgements}

We are grateful to Atilla Akgül, one of the staff of the Sakarya Provincial Health Directorate, for his contributions to the data collection.

\section{REFERENCES}

1. Bartley G. Acquired Lacrimal Drainage Obstruction. Ophthal Plast Reconstr Surg. 1993; 9(1): 11-26, doi: 10.1097/00002341-19930300000002, indexed in Pubmed: 1476972.

2. Busse H, Müller KM. [Development of idiopathic dacryostenosis (clinical and pathologico-anatomical findings)]. Klin Monbl Augenheilkd. 1977; 170(4): 627-632, indexed in Pubmed: 886804.

3. Linberg JV, McCormick SA. Primary acquired nasolacrimal duct obstruction. A clinicopathologic report and biopsy technique. Ophthalmology. 1986; 93(8): 1055-1063, doi: 10.1016/s0161-6420(86)33620-0, indexed in Pubmed: 3763155.

4. Mauriello JA, Palydowycz S, DeLuca J. Clinicopathologic study of lacrimal sac and nasal mucosa in 44 patients with complete acquired nasolacrimal duct obstruction. Ophthalmic Plast Reconstr Surg. 1992; 8(1): 13-21, doi: 10.1097/00002341-199203000-00002, indexed in Pubmed: 1554647.

5. Tamhane UU, Aneja S, Montgomery D, et al. Association between admission neutrophil to lymphocyte ratio and outcomes in patients with acute coronary syndrome. Am J Cardiol. 2008; 102(6): 653-657, doi: 10.1016/j.amjcard.2008.05.006, indexed in Pubmed: 18773982.

6. Akdag S, Akyol A, Asker M, et al. Platelet-to-Lymphocyte Ratio May Predict the Severity of Calcific Aortic Stenosis. Med Sci Monit. 2015; 21: 3395-3400, doi: $10.12659 / \mathrm{msm} .894774$, indexed in Pubmed: 26544152.
7. Akboga MK, Canpolat U, Yuksel M, et al. Platelet to lymphocyte ratio as a novel indicator of inflammation is correlated with the severity of metabolic syndrome: A single center large-scale study. Platelets. 2016; 27(2): 178-183, doi: 10.3109/09537104.2015.1064518, indexed in Pubmed: 26196312.

8. Tsiara S, Elisaf M, Jagroop IA, et al. Platelets as predictors of vascular risk: is there a practical index of platelet activity? Clin Appl Thromb Hemost. 2003; 9(3): 177-190, doi: 10.1177/107602960300900301, indexed in Pubmed: 14507105.

9. Azab B, Daoud J, Naeem FB, et al. Neutrophil-to-lymphocyte ratio as a predictor of worsening renal function in diabetic patients (3-year follow-up study). Ren Fail. 2012; 34(5): 571-576, doi: 10.3109/0886 022X.2012.668741, indexed in Pubmed: 22452450.

10. Azab B, Shah N, Akerman M, et al. Value of platelet/lymphocyte ratio as a predictor of all-cause mortality after non-ST-elevation myocardial infarction. J Thromb Thrombolysis. 2012; 34(3): 326-334, doi: 10.1007/ s11239-012-0718-6, indexed in Pubmed: 22466812.

11. Ryu HJ, Seo MiR, Choi HJ, et al. Mean platelet volume as a marker for differentiating disease flare from infection in Behçet's disease. Int $\mathrm{J}$ Rheum Dis. 2018; 21(8): 1640-1645, doi: 10.1111/1756-185X.13008, indexed in Pubmed: 27886446.

12. Yayla Ç, Açikgöz SK, Yayla KG, et al. The association between plateletto-lymphocyte ratio and inflammatory markers with the severity of aortic stenosis. Biomark Med. 2016; 10(4): 367-373, doi: 10.2217/ bmm-2015-0016, indexed in Pubmed: 26974393.

13. Racz JM, Cleghorn MC, Jimenez MC, et al. Predictive Ability of Blood Neutrophil-to-Lymphocyte and Platelet-to-Lymphocyte Ratios in Gastrointestinal Stromal Tumors. Ann Surg Oncol. 2015; 22(7): 2343-2350, doi: 10.1245/s10434-014-4265-6, indexed in Pubmed: 25472648.

14. Yin $Y$, Wang J, Wang $X$, et al. Prognostic value of the neutrophil to lymphocyte ratio in lung cancer: A meta-analysis. Clinics (Sao Paulo). 2015; 70(7): 524-530, doi: 10.6061/clinics/2015(07)10, indexed in Pubmed: 26222823.

15. Alan S, Tuna S, Türkoğlu EB. The relation of neutrophil-to-lymphocyte ratio, platelet-to-lymphocyte ratio, and mean platelet volume with the presence and severity of Behçet's syndrome. Kaohsiung J Med Sci. 2015; 31(12): 626-631, doi: 10.1016/j.kjms.2015.10.010, indexed in Pubmed: 26709224.

16. Mercan R, Bitik B, Tufan A, et al. The Association Between Neutrophil/ Lymphocyte Ratio and Disease Activity in Rheumatoid Arthritis and Ankylosing Spondylitis. J Clin Lab Anal. 2016; 30(5): 597-601, doi: 10.1002/jcla.21908, indexed in Pubmed: 26666737.

17. Zahorec $R$. Ratio of neutrophil to lymphocyte counts--rapid and simple parameter of systemic inflammation and stress in critically ill. Bratisl Lek Listy. 2001; 102(1): 5-14, indexed in Pubmed: 11723675.

18. Koseoglu HI, Altunkas F, Kanbay A, et al. Platelet-lymphocyte ratio is an independent predictor for cardiovascular disease in obstructive sleep apnea syndrome. J Thromb Thrombolysis. 2015; 39(2): 179-185, doi: 10.1007/s11239-014-1103-4, indexed in Pubmed: 25002338.

19. Unal D, Eroglu C, Kurtul N, et al. Are neutrophi//ymphocyte and platelet/ lymphocyte rates in patients with non-small cell lung cancer associated with treatment response and prognosis? Asian Pac J Cancer Prev. 2013; 14(9): 5237-5242, doi: 10.7314/apjcp.2013.14.9.5237, indexed in Pubmed: 24175807.

20. Akkaya E, Gul M, Ugur M. Platelet to lymphocyte ratio: a simple and valuable prognostic marker for acute coronary syndrome. Int J Cardiol. 2014; 177(2): 597-598, doi: 10.1016/j.ijcard.2014.08.143, indexed in Pubmed: 25220175.

21. Akboga MK, Canpolat U, Yayla C, et al. Association of Platelet to Lymphocyte Ratio With Inflammation and Severity of Coronary Atherosclerosis in Patients With Stable Coronary Artery Disease. Angiology. 2016; 67(1): 89-95, doi: 10.1177/0003319715583186, indexed in Pubmed: 25922197.

22. Lian L, Xia YY, Zhou C, et al. Application of platelet/lymphocyte and neutrophi//ymphocyte ratios in early diagnosis and prognostic prediction in patients with resectable gastric cancer. Cancer Biomark. 2015; 15(6): 899-907, doi: 10.3233/CBM-150534, indexed in Pubmed: 26444485.

23. Sunbul M, Gerin F, Durmus $E$, et al. Neutrophil to lymphocyte and platelet to lymphocyte ratio in patients with dipper versus non-dipper 
hypertension. Clin Exp Hypertens. 2014; 36(4): 217-221, doi: 10.310 9/10641963.2013.804547, indexed in Pubmed: 23786430.

24. Inagaki N, Kibata K, Tamaki T, et al. Prognostic impact of the mean platelet volume/platelet count ratio in terms of survival in advanced non-small cell lung cancer. Lung Cancer. 2014; 83(1): 97-101, doi: 10.1016/j.lungcan.2013.08.020, indexed in Pubmed: 24189108.

25. Kisacik B, Tufan A, Kalyoncu U, et al. Mean platelet volume (MPV) as an inflammatory marker in ankylosing spondylitis and rheumatoid arthritis. Joint Bone Spine. 2008; 75(3): 291-294, doi: 10.1016/j. jbspin.2007.06.016, indexed in Pubmed: 18403245.

26. Bowman SJ. Hematological manifestations of rheumatoid arthritis. Scand J Rheumatol. 2002; 31(5): 251-259, doi: 10.1080/03009740 2760375124, indexed in Pubmed: 12455813.

27. Bertero MT, Caligaris-Cappio F. Anemia of chronic disorders in systemic autoimmune diseases. Haematologica. 1997; 82(3): 375-381, indexed in Pubmed: 9234597.
28. Bath P, Algert C, Chapman N, et al. PROGRESS Collaborative Group. Platelet size: measurement, physiology and vascular disease. Blood Coagul Fibrinolysis. 1996; 7(2): 157-161, indexed in Pubmed: 8735807.

29. Bath P, Algert C, Chapman N, et al. PROGRESS Collaborative Group. Association of mean platelet volume with risk of stroke among 3134 individuals with history of cerebrovascular disease. Stroke. 2004; 35(3): 622-626, doi: 10.1161/01.STR.0000116105.26237.EC, indexed in Pubmed: 14976328.

30. Endler G, Klimesch A, Sunder-Plassmann H, et al. Mean platelet volume is an independent risk factor for myocardial infarction but not for coronary artery disease. Br J Haematol. 2002; 117(2): 399-404, doi: 10.1046/j.1365-2141.2002.03441.x, indexed in Pubmed: 11972524.

31. Kapsoritakis AN, Koukourakis MI, Sfiridaki A, et al. Mean platelet volume: a useful marker of inflammatory bowel disease activity. Am J Gastroenterol. 2001; 96(3): 776-781, doi: 10.1111/j.15720241.2001.03621.x, indexed in Pubmed: 11280550. 